\title{
DOCUMENTAÇÃO FOTOGRÁFICA DAS OBRAS DE ENGENHARIA DO SÉCULO XIX
}

\author{
THE PHOTOGRAPHIC DOCUMENTATION OF \\ NINETEENTH CENTURY ENGINEERING PROJECTS
}

A fotografia com finalidade documental produzida no século XIX, e dentro dela a fotografia de arquitetura e a fotografia de engenharia, vem despertando nos últimos anos a atenção de curadores de museus e de coleções fotográficas, bem como de historiadores da fotografia, da arquitetura ou da tecnologia. Em 1983, uma exposição em Paris, intitulada 'Photo Génie' e organizada pelo Centre National de la Photographie e pela École Nationale des Ponts et Chaussées, abriu caminho para uma série de exposições e projetos nessa área. Dez anos depois, fotografias que até então não haviam merecido divulgação mais ampla foram trazidas a público em diversas exposições e catálogos dedicados ao tema, indicando o aumento de interesse em torno dessa produção fotográfica tão singular. No ano de 1994, por exemplo, foram montadas pelo menos três grandes exposições sobre o tema: em Paris, a exposição 'Photographier l'Architecture: 1851-1920' apresentou fotografias inéditas do patrimônio histórico e arquitetônico da França, pertencentes à coleção do Musée National de Monuments Français; em Nova York, a exposição 'Tracking the West: A. J. Russel Photographs of the Union Pacific Railroad', com dezenas de originais do século XIX retratando as estradas de ferro e o Oeste americano, podia ser vista na The New York Public Library Third Floor Galery; e ainda naquele mesmo ano, o Metropolitan Museum of Art (Nova York), em conjunto com o Canadian Centre for Architecture (Montreal) e com o Musée National de Monuments Français (Paris) inaugurou uma exposição, acompanhada de um precioso catálogo, com a obra ainda pouco conhecida do francês Edouard-Denis Baldus (1813-89), um dos pioneiros nesse gênero de fotografia.

As imagens publicadas nessa edição foram obtidas durante pesquisa que desenvolvo para tese de doutorado na Faculdade de Arquitetura e Urbanismo da Universidacle de São Paulo. As imagens aqui apresentadas tratam exatamente da atividade de documentação fotográfica das obras de engenharia realizadas durante o Segundo Reinado, isto é, no período compreendido entre a chegada da fotografia no Brasil, em 1840, e o fim da monarquia, em 1889. No projeto em questão, esse gênero de fotografia, produzido no Brasil por fotógrafos como Marc Ferrez, Benjamin R. Mulock, Augusto Stahl, entre outros, não está sendo investigado como ilustração para o estudo da engenharia e arquitetura brasileiras no século passado, mas como um tema em si mesmo. $O$ interesse pela documentação fotográfica dos projetos de engenharia dessa época não se situa na 'rememoração' daquelas obras e realizações, isto é, na possibilidade de 'recuperar', pela memória e para a história, esse passado em particu- 
lar, documentado através de fotografias. Na verdade, o importante é a possibilidade de identificar, nesse passado, através dessa produção fotográfica, um projeto de memorização daquelas obras e realizações. Um projeto, inclusive, do qual participaram as principais instituições formadoras da chamada "memória nacional" (Instituto Histórico e Geográfico Brasileiro, Biblioteca Nacional, Sociedade Auxiliadora da Indústria Nacional etc.), bem como o imperador d. Pedro II.

O tema que me desperta interesse, portanto, é o próprio ato de documentar, 'fotograficamente', em determinado contexto, e não apenas o resultado dessa ação. Por isto, procuro conhecer e analisar, através das imagens fotográficas e de outros documentos da época, as condições, os atores e os processos que resultaram na formação e na preservação de uma determinada memória dos principais empreendimentos realizados no Império que se situavam no campo da engenharia e atividades afins (construção de portos e estradas de ferro, melhoramentos urbanos na Corte e nas províncias, introdução de inovações técnicas no campo e nas cidades, realização de expedições científicas e de exposições nacionais etc.). Nesse sentido, ao investigar o papel da atividade fotográfica registrando os projetos de engenharia do Império, pretende-se avaliar também em que medida tal atividade pode ser considerada como parte de um esforço consciente para legar à sociedade e às gerações futuras, como patrimônio coletivo, uma certa memória daquelas realizações e, portanto, do próprio progresso, tal como ele era visto e compreendido no século XIX. As imagens apresentadas a seguir foram extraídas de livros, gravuras e fotografias produzidas ao longo desse período, no Brasil e no exterior (as reproduções fotográficas foram realizadas por Francisco da Costa).

\section{Figura 1}

Cientista inglês, membro da Royal Society e diretor dos arquivos mineralógicos do Museu de Geologia Prática de Londres, Robert Hunt (1807-87) foi também um dos pioneiros da história da fotografia na Inglaterra, ao lado de sir John Herschel e do próprio William Henry Fox Talbot, inventor do calótipo.

Em 1841, escreveu $A$ popular treatise on the art of photography, including daguerreotype and all the new methods of producing pictures by chemical agency of light, o primeiro 'manual de fotografia' propriamente dito, publicado na Inglaterra, no qual Hunt apresenta a história e a descrição prática de vários processos fotográficos recémdescobertos. Dezenas de manuais de fotografia foram publicados, ao longo do século XIX, sobretudo na França, onde o ensino da fotografia foi amplamente difundido, inclusive nas escolas de engenharia.

\section{Foto 2}

$\mathrm{Na}$ École Nationale des Ponts et Chaussées, criada em Paris em 1747 e modelo para outras instituições do gênero em todo o mundo, o ensino da fotografia foi introduzido em 1857 e só foi suprimido em 1911. Em 1872, o francês Louis-Alphonse Davanne (1824-1912) - químico, fotógrafo e pesquisador dedicado ao desenvolvimento do meio - tornou-se professor de fotografia dos estudantes de engenharia da escola. Na Sorbonne, Davanne também fez palestras sobre o assunto em 1879 e em 1881, e no Conservatoire des Arts et Métiers participou da série de "conferências públicas sobre fotografia" organizadas pela instituição, entre 1891 e 1892. Além do resumo de seus 
cursos e conferências, Davanne publicou manuais de fotografia bastante populares em sua época, como a obra em co-autoria com Charles Louis Barreswil, intitulada Chimie photographique (Paris, Mallet-Bachelier, 1854), reeditada súcessivamente em 1859, 1861 e 1864, e o clássico La photographie; traité théorique et pratique (Paris, Gauthier-Villars, 2 vols., 1886-88). Essas e outras obras de difusão da fotografia também foram introduzidas no Brasil, onde passaram a integrar o acervo da Biblioteca Nacional e de instituições como a antiga Escola Politécnica do Rio de Janeiro, criada em 1874, e o Clube de Engenharia, criado em 1880.

\section{Foto 3}

Numa época em que muitos fotógrafos ainda lutavam para que seu ofício fosse reconhecido como manifestação artística, a fotografia documental (e, dentro dela, a fotografia de obras de engenharia) parecia orgulhosa de sua capacidade de representar fielmente a realidade, com todas as nuanças e variações de tom possiveis, criando um campo de trabalho promissor para os fotógrafos da segunda metade do século XIX e uma linguagem própria desse gênero de fotografia. Entre tantos profissionais que, no mundo todo, se ocuparam da documentação fotográfica de pontes, viadutos, estradas e outras construções da época - as chamadas 'obras de arte' do engenheiro - , o francês Auguste Hipollyte Collard (1812-c.1887) tornou-se especialista no assunto, chegando a se fazer anunciar pelo título de "fotógrafo de pontes e calçadas". Acompanhando as diferentes fases de construção de uma obra ou registrando a sua conclusão, ilustrando álbuns e relatórios de empresas ou a própria tecnologia desenvolvida nas escolas politécnicas, a fotografia transformou-se num instrumento de grande utilidade para o engenheiro do século XIX e, ao meśmo tempo, num veículo de divulgação do seu campo profissional.

\section{Foto 4}

O principal mercado de trabalho para os engenheiros do século XIX eram as estradas de ferro, atividade que também empregava vários fotógrafos, particularmente nos Estados Unidos, onde as ferrovias e as expedições exploratórias desempenharam um papel importante na expansão para o Oeste. Milhares de fotografias foram produzidas para documentar as paisagens desconhecidas da região, bem como a construção de pontes e estações, o assentamento de trilhos e dormentes, a passagem de locomotivas. Em meio a tantas imagens, a fotografia de Andrew Joseph Russell (1830-1902) registrando "o 'aperto de mãos' entre o Leste e o Oeste", no dia 10 de maio de 1869, ficaria famosa: a cena, longamente preparada, comemora a junção das obras da Union Pacific Railroad Company, para a qual Russell trabalhava, com as da Central Pacific Railroad Company, que também tinha ali um fotógrafo a seu serviço (Alfred Hart). As duas locomotivas que quase se tocam, as autoridades perfiladas e alguma 'descontração' entre os trabalhadores emolduram o gesto simbólico que centraliza a imagem, encenado pelos dois engenheiros-chefe das duas companhias.

\section{Fotos 5 e 6}

Com a construção de ferrovias no Brasil, a partir de meados do século passado, chegaram ao país, vindos da Inglaterra, não só os capitais que iriam financiar essas estradas, como também boa parte da mão-de-obra encarregada de realizá-las: emprei- 
teiros, engenheiros, contramestres, capatazes, feitores de turma, mestres-de-obras e operários. De lá também vieram para o Brasil alguns fotógrafos, provavelmente em busca de um mercado menos competitivo ou, não se sabe ao certo, em razão mesmo dos empreendimentos ingleses no país. Pioneiros nessa atividade entre nós, Augusto Stahl, alemão ativo no Brasil entre 1853 e 1867, e Benjamin R. Mulock, inglês ativo no Brasil entre 1858 e 1861, documentaram na década de 1850, a serviço de duas companhias inglesas, as instalações e os trabalhos de construção das primeiras estradas de ferro da região Nordeste. A locomotiva com o indivíduo capaz de manejá-la e a passagem erguida provisoriamente, em contraste com a sólida estrutura de uma ponte em construção, integram um conjunto de imagens destinado não só aos relatórios técnicos de tais empresas, como também à formação de uma memória desses empreendimentos. Ao imperador d. Pedro II, o Instituto Photographico de Stahl e C. ofereceu, em 1861, um álbum de 34 vistas, cujo título era Memorandum pittoresco de Pernambuco, onde incluiu várias fotografias da Recife and São Francisco Railway Company. No mesmo ano, o empreiteiro inglês John Watson também presentearia o imperador com um álbum de 46 vistas (produzidas por Mulock) da estrada de ferro da qual era o concessionário exclusivo, a Bahia and São Francisco Railway Company.

\section{Fotos 7, 8 e 9}

O maior fotógrafo brasileiro do século XIX, cuja produção está intimamente associada à paisagem do Rio de Janeiro no século passado e início deste, foi também o fotógrafo que mais trabalhou na documentação das obras públicas do Império não só na Corte, como no restante do país. Agraciado com o título de fotógrafo da Marinha Imperial e da Comissão Geológica, Marc Ferrez (1843-1923), viajando pelo Brasil, fotografou para a São Paulo Railway Company (a Santos - Jundiaí), para a Estrada de Ferro Paranaguá-Curitiba, para a Estrada de Ferro Thereza Christina (Santa Catarina) e para a Estrada de Ferro D. Pedro II (Rio - Minas Gerais). No Rio de Janeiro, entre outros projetos de engenharia e arquitetura da época, ele registrou o sistema de abastecimento d'água instalado no morro do Pedregulho e a estrada de ferro do Corcovado, além da sede da Estrada de Ferro D. Pedro II e do prédio do Ministério da Agricultura, Comércio e Obras Públicas. Considerada uma das obras ferroviárias "mais notáveis" do país, a Estrada de Ferro Paranaguá - Curitiba foi construída entre 1880 e 1884 e nela trabalharam os engenheiros Antônio Rebouças, João Teixeira Soares e Francisco Pereira Passos. A documentação produzida por Ferrez, particularmente no caso dessa estrada, é tão impressionante quanto os enormes paredões de pedra e os acentuados desniveis da serra do Marumbi vencidos pela Paranaguá - Curitiba, com seus "túneis encarreirados, viadutos que se sucedem [e] pontes que se estendem uma após a outra" (Jornal do Commercio, dezembro de 1884).

\section{Figura 10 e Foto 11}

Os projetos de engenharia que, de um modo geral, estavam mudando a paisagem das cidades e do mundo tiveram ampla divulgação, a partir de meados do século XIX, através das imagens publicadas em livros e periódicos ilustrados por litogravuras e, posteriormente, já no final do século, por fotografias impressas. Jornais de divulgação científica, como o Scientific American (EUA), o La Nature (França) e o De Natuur (Alemanha), entre outros, traziam matérias anunciando e ilustrando as conquistas mais 
recentes da ciência e da técnica modernas. Os novos inventos e as 'proezas' do homem desafiando a natureza apareciam em destaque, como a cena da primeira travessia realizada em 1876 entre os dois pilares da ponte do Brooklyn, por um dos engenheiros que trabalhavam na sua construção. Longe de ficar restrita aos relatórios técnicos e aos álbuns de empresas, a fotografia de pontes, túneis e viadutos das estradas de ferro, tanto quanto as imagens de outras obras de engenharia da época, tiveram uma circulação mais ampla no conjunto da sociedade. Esse gênero de fotografia freqüentava não só as exposições universais, de belas-artes ou de fotografia, como também os salões das residências, onde costumava ser colecionado no formato estereoscópico. Produzidos aos milhares, os cartões estereoscópicos foram, até fins do século passado, o maior veículo de popularização da fotografia documental, de paisagem e vistas urbanas. Acrescentando relevo e profundidade à imagem fotográfica, o cartão estereoscópico tornava ainda mais concreta e familiar uma realidade que se transformava tão radicalmente por força da tecnologia.

Maria Inez Turazzi Pesquisadora do Instituto do Patrimônio Histórico e Artístico Nacional (Iphan) Rua General Glicério, 364 apto. 301 Rio de Janeiro - RJ 22451-020 


\section{REFERÊNCIAS BIBLIOGRÁFICAS}

Carlebach, Michael L. The origins of photojournalism in America. Washington e Londres, 1992 Smithsonian Institution Press.

Ferrez, Gilberto 1989

Ferrez, Gilberto Bahia: velhas fotografias, 1858-1900. $2^{\text {a }}$ ed., Rio de Janeiro/Salvador/Kosmos, Banco da Bahia Investimentos.

1985

A fotografia no Brasil: 1840-1900. Rio de Janeiro, Funarte/Pró-Memória.

Ferrez, Gilberto e

Weston J.

1976

Hunt, Robert

1973

1983

Pioneer photographers of Brazil: 1840-1920. Nova York, The Center Inter-American Relations.

A popular treatise on the art of photography: A fac-simile edition with introduction and notes by James Yingpeh Tong. Athens, Ohio University Press.

'Le Grand Guvre; photographies des grands travaux: 1860-1900'. Photo Poche. Introdução de Jean Desjours. Paris, Centre National de la Photographie.

1994

'Photographier l'architecture 1851-1920'. Collection du Musée des Monuments Français. Paris, Éditions de la Réunion des Musées Nationaux.

Sandweiss, Martha A. Pbotography in nineteenth century America. Forth Worth/Nova York, Amon Carter (org.).

1991

Museum/Harry N. Abrams.

Vries, Leonard de

1991

Victorian inventions. Londres, John Murray. 

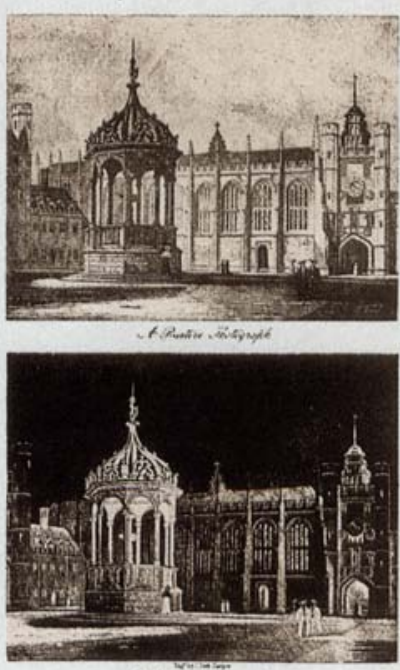

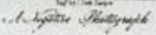

A POPULAR TREITISE

$+\cdots$

ART OF PHOTOGRAPHY.

DAGUBRRÉOTYPE,

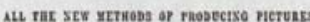

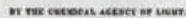

ROBRRT HUWT,

aLAseor

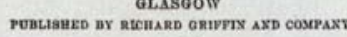

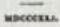

Figura 1: Folha de rosto da obra de Robert Hunt, publicada em 1841 (Edição fac-similar. Coleção da autora).

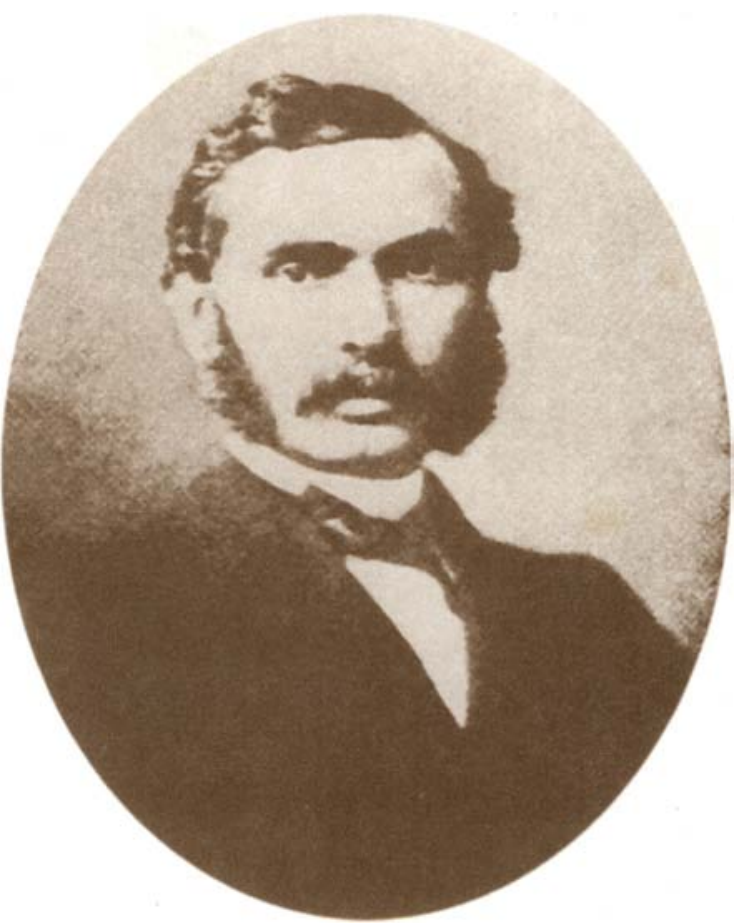

Foto 2: Retrato de Louis-Alphonse Davanne por Lafon de Camarsac (1821-1905). Esmalte fotográfico, 1867 (Société Française de Photographie). 


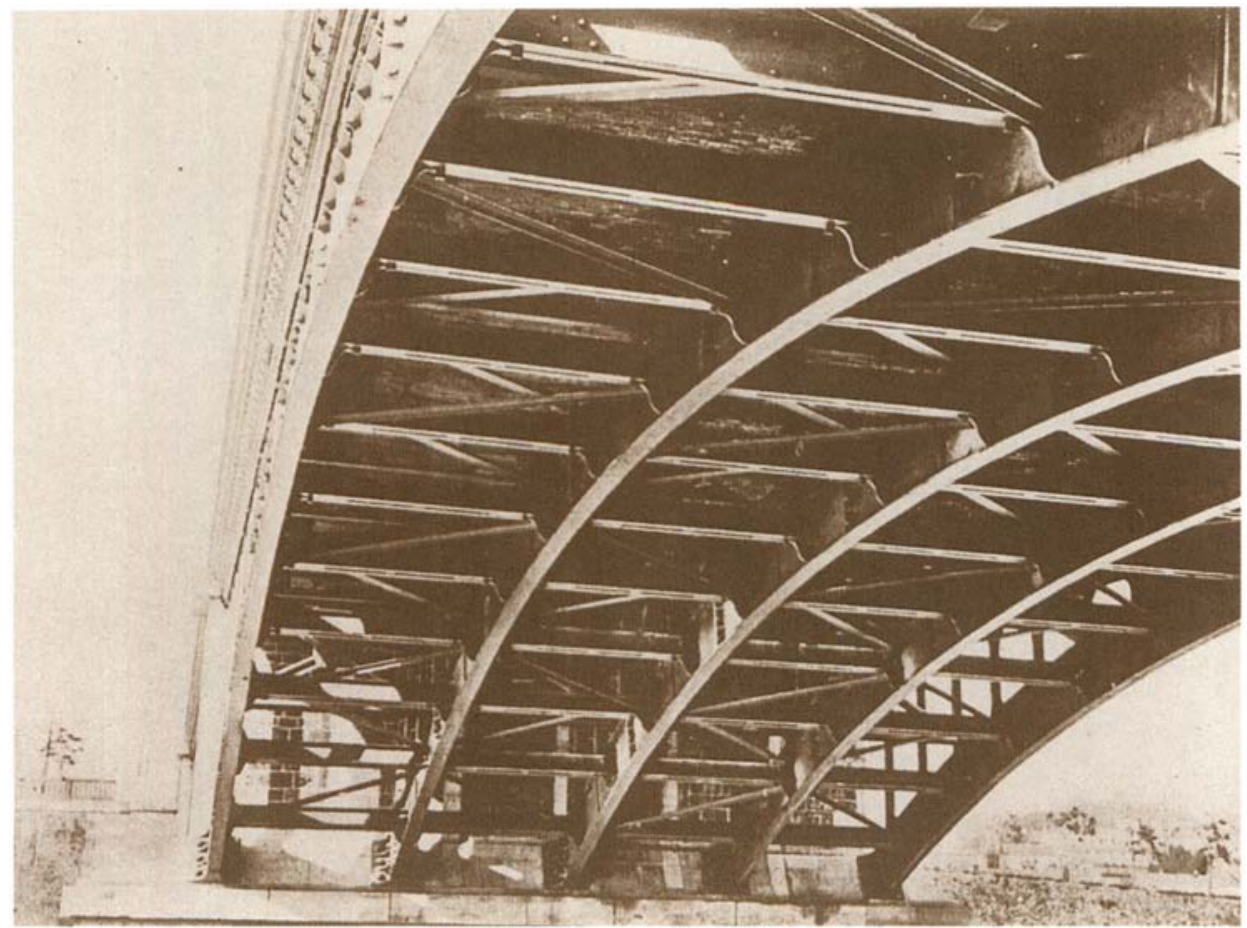

Foto 3: O arco da ponte de Grenelle, em Paris, por Auguste Hipollyte Collard, Albúmen, 1874 (École Nationale de Ponts e Chaussées).

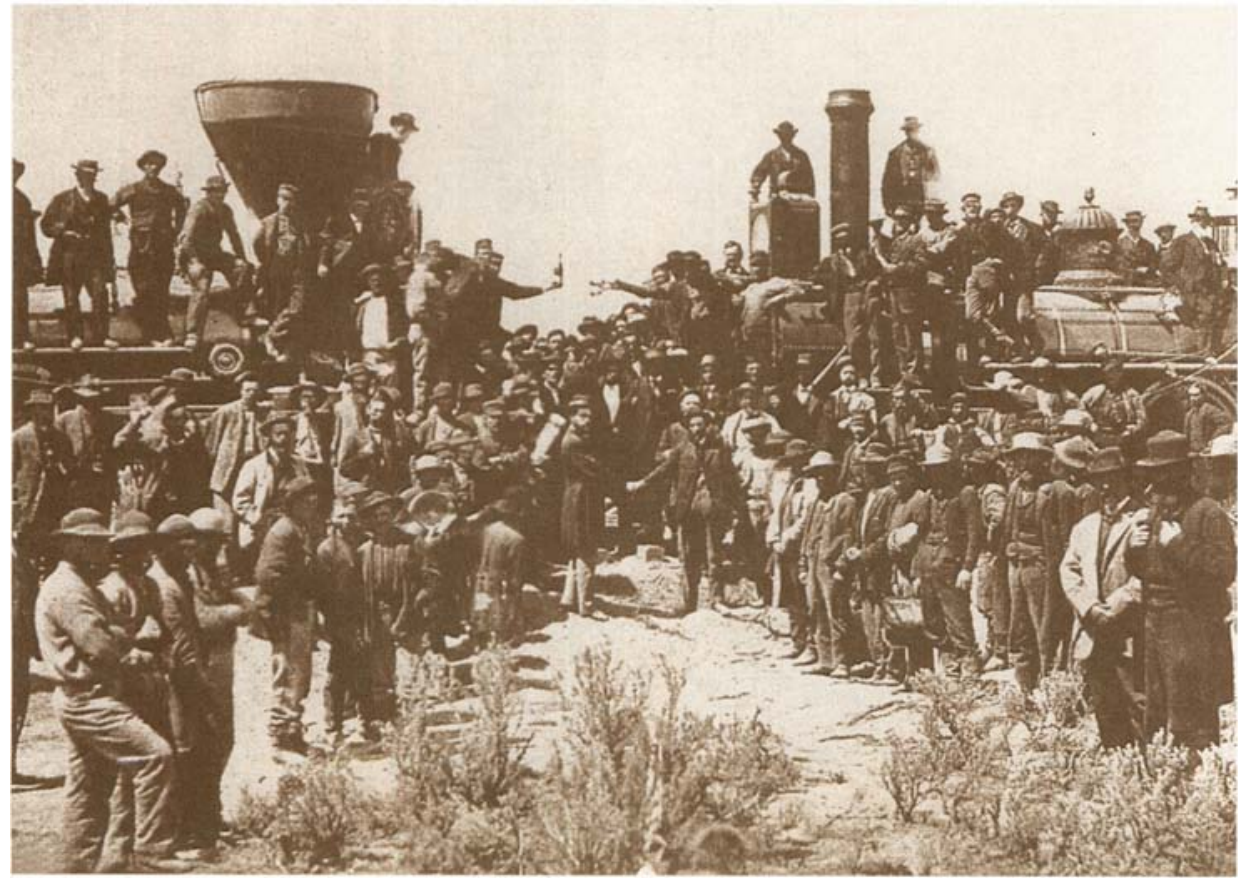

Foto 4: O encontro de duas ferrovias em Promontory Point (Utah, EUA), por Andrew Joseph Russell, Albúmen, 1869 (Union Pacific Museum Collection [Omaha, EUA]). 


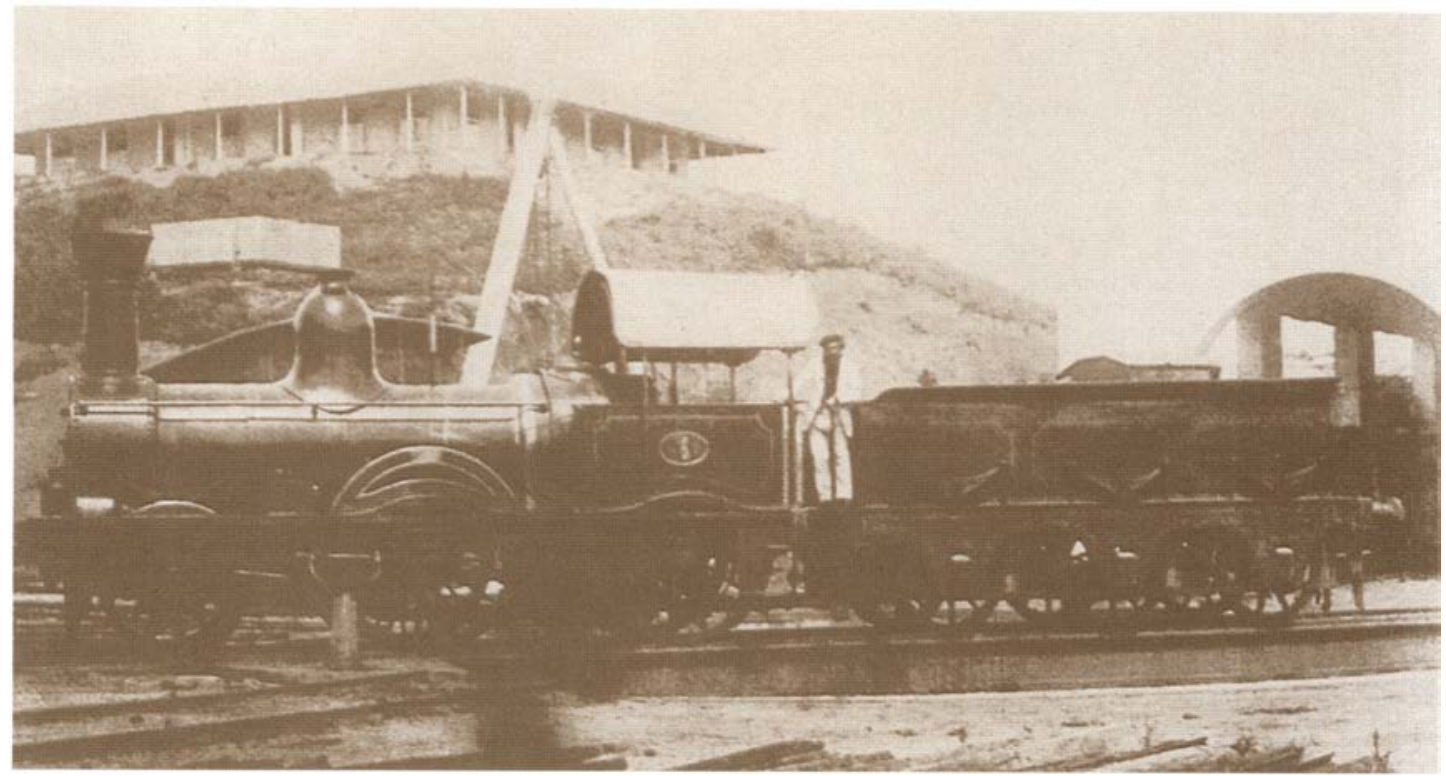

Foto 5: Locomotiva da Recife and São Francisco Railway Company, por Augusto Stahl, Albúmen, 1858 (Coleçāo Gilberto Ferrez).

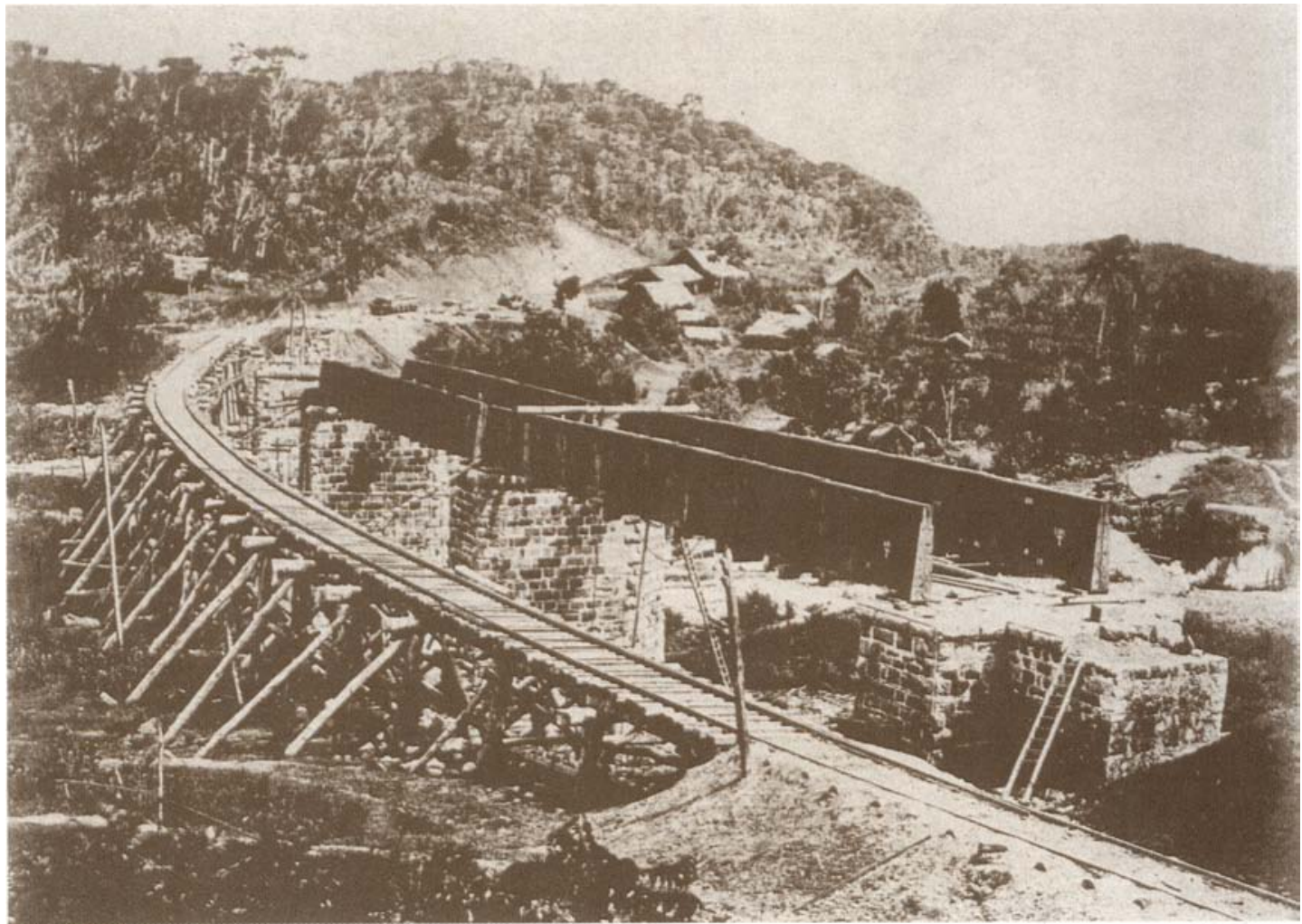

Foto 6: Ponte ferroviária da Bahia and São Francisco Railway Company, por Benjamin R. Mulock, Albúmen, c. 1859 (Biblioteca Nacional). 


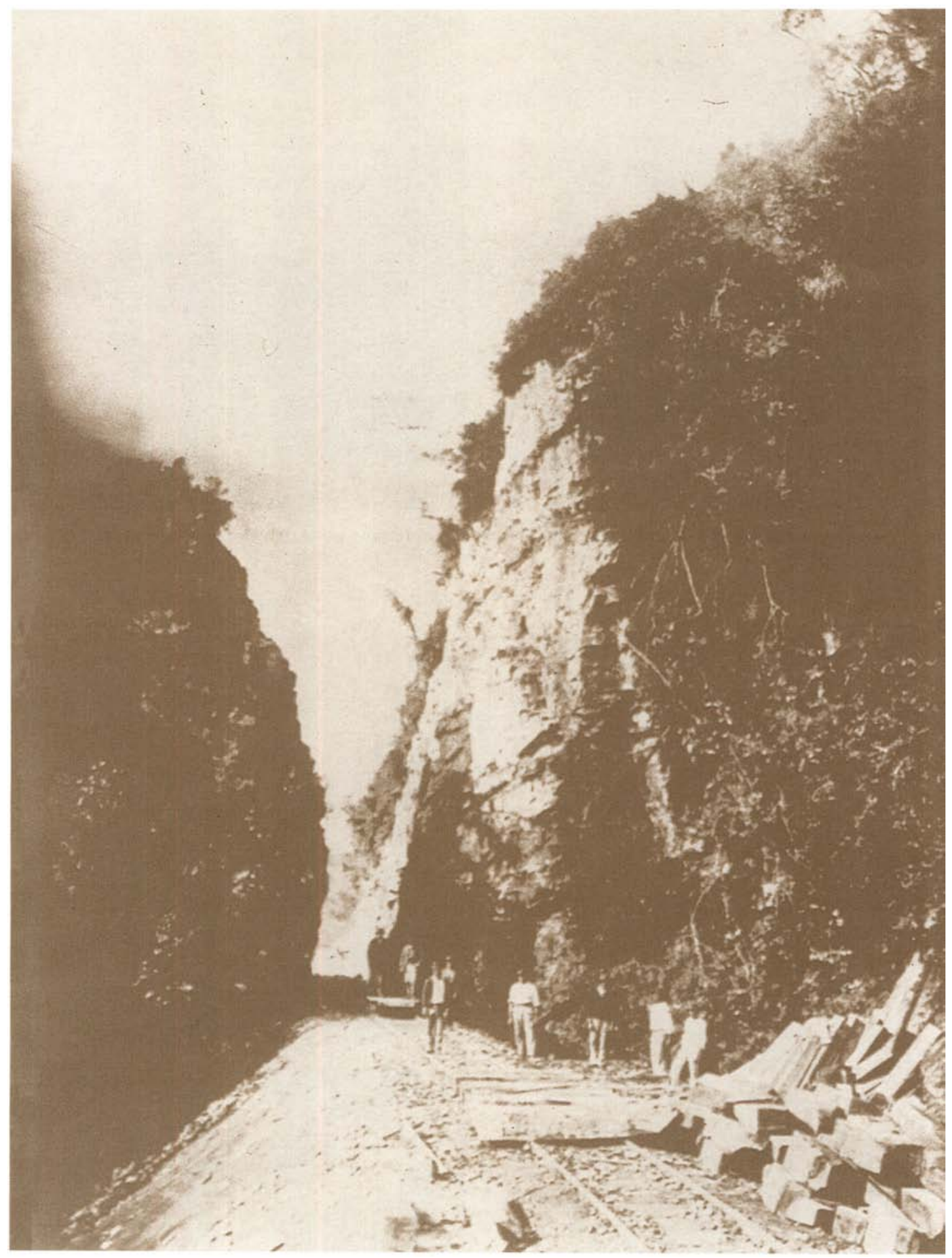

Foto 7: Obras de construção da ferrovia Paranaguá - Curitiba, por Marc Ferrez, Albúmen, c. 1882 (Coleção Gilberto Ferrez). 


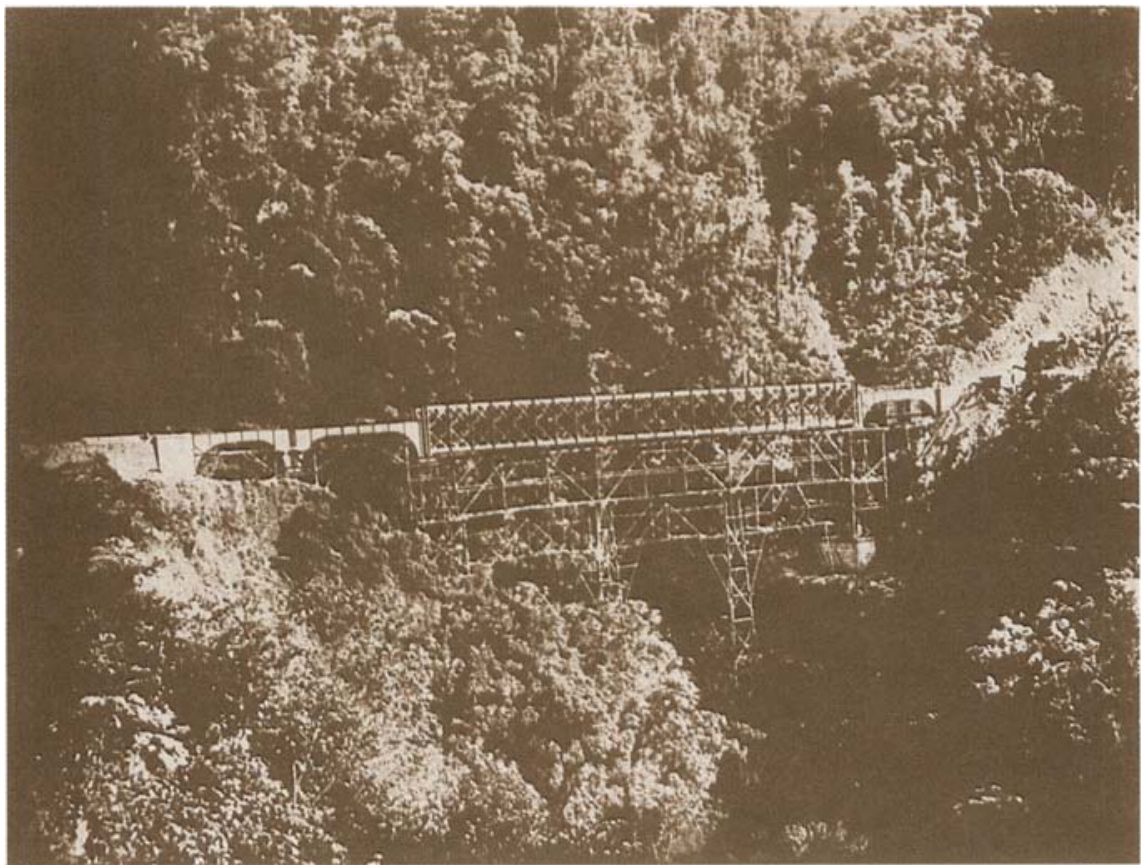

Foto 8: Viaduto em construção da ferrovia Paranaguá - Curitiba, por Marc Ferrez, Albúmen, c. 1882 (Coleção Gilberto Ferrez).

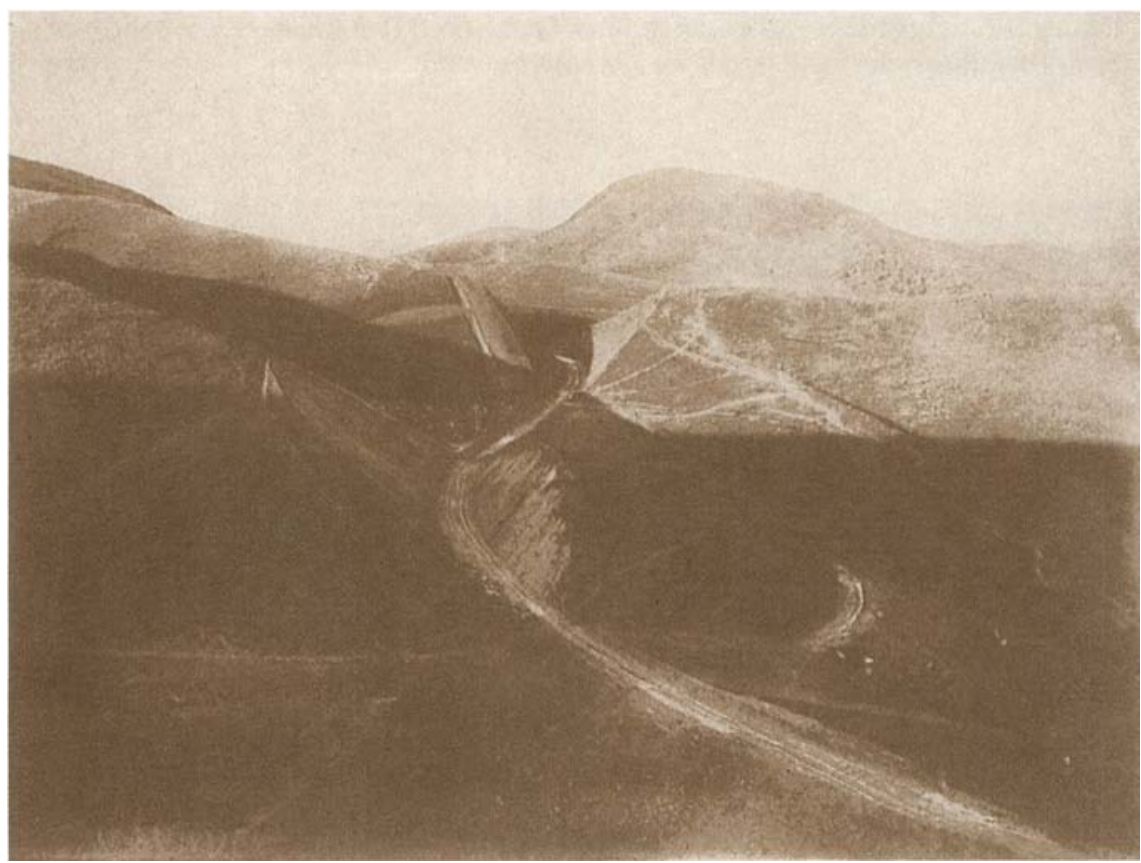

Foto 9: Terraplenagem para a ferrovia Paranaguá - Curitiba, Marc Ferrez, Albúmen, c.1882 (Coleçāo Gilberto Ferrez). 


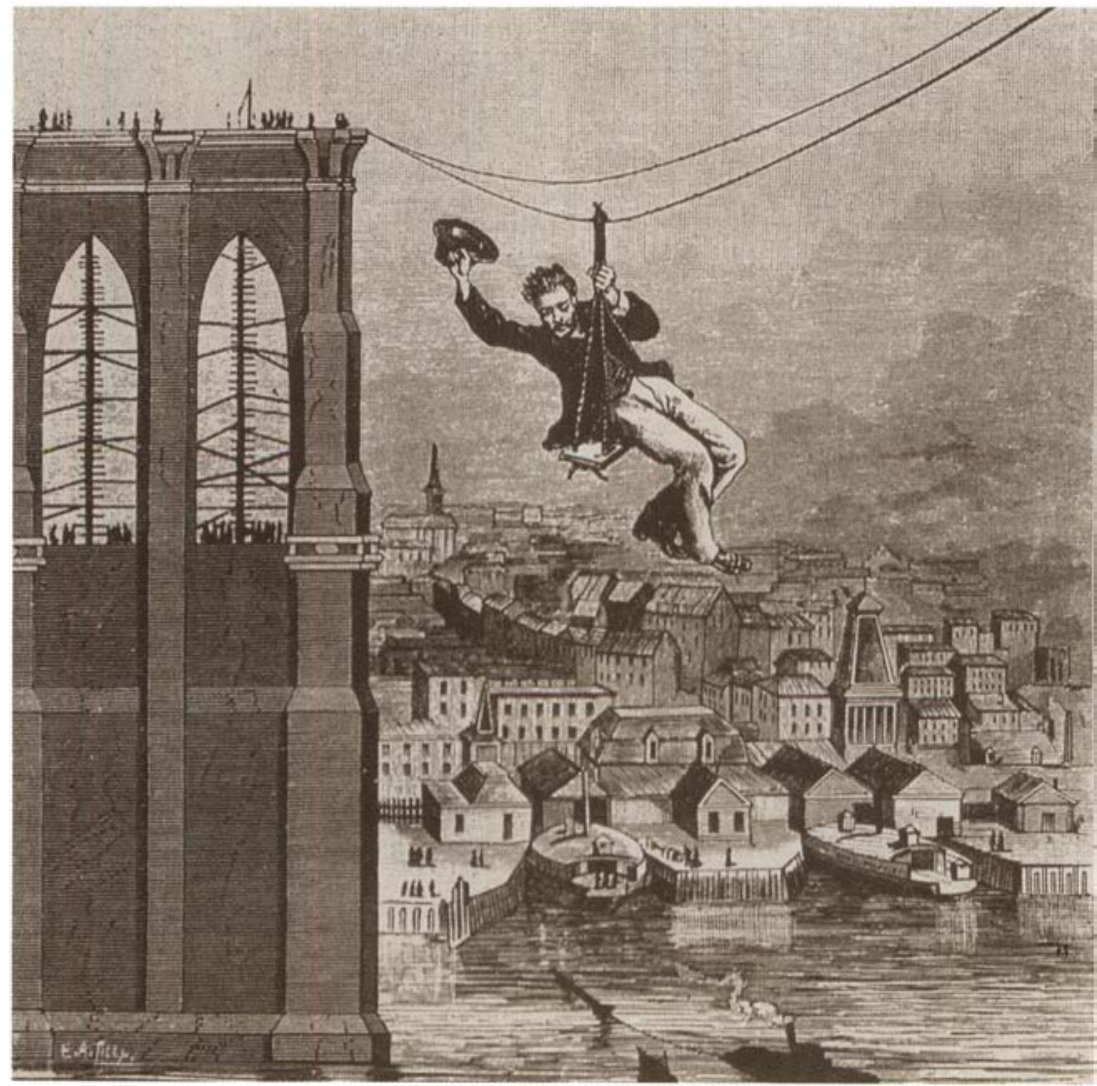

Figura 10: A construção da ponte do Brooklyn, sobre East River, Nova York, por E. A. Tilly (ilustrador), publicada no De Natuur, 1883.

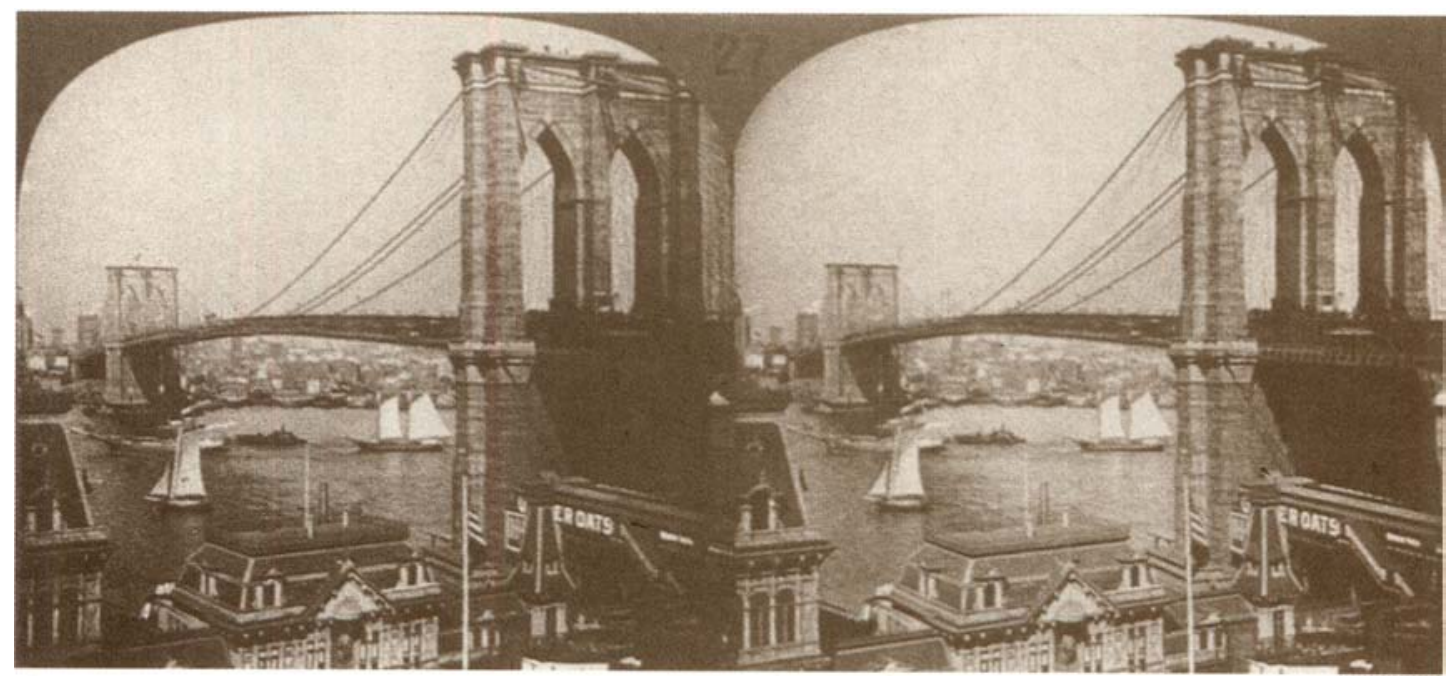

Foto 11: A ponte do Brooklyn e a cidade de Nova York, por fotógrafo desconhecido. Cartão estereoscópico com fotografia sobre papel de gelatina, 1900 (Amon Carter Museum [Forth Worth, EUA]). 